\title{
Uma análise da concretude da atividade de ensino de matemática no ensino fundamental ${ }^{1}$
}

\author{
An analysis of concreteness math education activity in elementary \\ education
}

\author{
Lucas Vieira Lemos ${ }^{2}$ \\ Ademir Damazio ${ }^{3}$
}

\section{RESUMO}

Esse artigo trata da análise de manifestações docentes que refletem atuações particulares na produção de modos de ensinar Matemática no Ensino Fundamental. Visa o debate a respeito da origem das objetivações geradoras dessa prática social e trazer ao plano o conteúdo das determinações subjetivas que dela derivam. As análises delimitam-se às revelações de professoras de matemática aposentadas e de pedagogas atuantes no ensino de matemática dos anos iniciais, que se manifestam sobre a posição docente e suas produções no cumprimento dessa função. Consideramos na análise as interações inerentes à prática imediata, ligada ao processo universal dessa atividade em que se inserem as professoras, isto é, a concretude das ligações necessárias que faz da atividade uma categoria essencial na investigação da prática humana. A preocupação é com os nexos da atividade de ensino, agentes da prática docente e, por consequência, do sentido pessoal que se expressa para o professor em sua atuação. Por esse viés emerge a reflexão em vista de respostas para a seguinte questão: que características do conteúdo objetivo da atividade são geradoras de sentidos e emoções do professor em atividade de ensino? Para tanto, foram selecionados recortes das falas de quatro entrevistas com professoras de matemática aposentadas e quatro com pedagogas que, por um diálogo com um roteiro semiestruturado de questões, relataram sobre suas práticas

\begin{abstract}
This article deals with the analysis of teacher demonstrations that reflect particular performances in the production methods of teaching mathematics in elementary school. Aims to enrich the debate about the origin of generational objectivations of this social practice and bring the plan the content of subjective determinations that derive from it. Analyses delimiting to the revelations of retired math teachers and pedagogical working in the teaching of mathematics in the early years, which manifest themselves on the teaching position and their productions in fulfilling this function. We consider in analyzing the interactions of the immediate practice linked to the universal process of this activity they are part of the teachers, that is, the concreteness of the necessary connections that make the activity an essential category in the investigation of human practice. The concern is the nexus of teaching activity, teaching practice agents and, therefore, the personal sense that is expressed for the teacher in his performance. For this way of view, emerges reflection in sense of answers to the question: what objective content of the characteristics of the activity are generating senses and emotions of the teacher in teaching activity? Therefore, the speeches clippings were selected from four interviews with retired math teachers and four pedagogues that for a dialogue with a semi-structured issues, reported on their teaching practices. These analyzes have emerged about reflections: the determinations of the subjective aspects of the teacher and the decisive character of the
\end{abstract}

\footnotetext{
${ }^{1}$ Artigo produzido a partir do estudo de Lemos (2014).

2 Mestre em Educação (UNESC), professor da Educação Básica da Rede Estadual de Santa Catarina.

3 Doutor em Educação (UFSC), professor do Programa de Pós-Graduação em Educação da UNESC.
} 
pedagógicas. Dessas análises surgiram reflexões acerca: das determinações dos aspectos subjetivos do professor e do caráter determinante dos elementos estruturais da atividade externa em sua individualidade. structural elements of foreign activity in their individuality.

Keywords: Education activity. Teacher. Scting.

Palavras-chave: Atividade de ensino. Professor. Atuação.

\section{Introdução}

Há muitas inquietações que nos instiga a pesquisar a prática pedagógica. No entanto, no presente estudo, a preocupação volta-se à análise dos elementos essenciais que estruturam internamente a atividade de ensino. Especificamente, centra-se no duplo efeito de dois componentes - motivo e finalidade - que expressam a aprendizagem na atividade externa e na subjetividade docente. Para tanto, a base é a tese da Psicologia Histórico-Cultural de que a gênese do desenvolvimento humano deriva da prática objetiva dos homens entre si e com o mundo (RUBINSTEIN, 1978; LEONTIEV, 2004). Nessa análise, surge a necessidade de abstração do motivo e finalidade da atividade, a fim de desvelar o conteúdo concreto que move e orienta professores e professoras à definição de ações e operações de ensino na prática pedagógica. Nesse âmbito, a aprendizagem surge como nexo coincidente e atuante desses dois elementos da estrutura da atividade de ensino (LEONTIEV, 1978): como a finalidade das ações e motivo de sua realização.

Para Leontiev (1978) e Davídov (1988), a atividade humana se estrutura nas relações externas que produzem os homens ao manipularem os objetos que satisfazem as necessidades coletivas e, com isso, se torna base e conteúdo da atividade interna. Estes elementos estruturais, segundo Davídov (1988), se originam nas transformações mútuas $(\rightleftarrows)$ entre os componentes 'peculiares' (necessidades $\rightleftarrows$ motivo $\rightleftarrows$ finalidade $\rightleftarrows$ condições), que unem os 'correlativos' (atividade $\rightleftarrows$ ação $\rightleftarrows$ operação). Esse processo transformativo se constitui numa espécie de dínamo e diretriz que, respectivamente, move e orienta a atuação dos sujeitos, determinados pelo tipo de relação com os objetos da atividade. Esse 
conjunto de pressupostos sustenta a tese de que a consciência resulta das relações sociais em que vivem os seres humanos: logo, também os professores.

Com o objetivo de promover o aprofundamento da reflexão, no que diz respeito ao objeto da pesquisa da atividade de ensino, revisitamos uma das seções de análise da dissertação intitulada $A$ Atividade do Professor e a Matemática no Ensino Fundamental: Uma Análise Sócio Histórica de Sua Estrutura e Conteúdo (Lemos, 2014) e retomamos o olhar analítico sobre as manifestações das professoras referentes à prática pedagógica com a seguinte questão: que características do conteúdo objetivo da atividade são geradoras de sentidos e emoções do professor em atividade de ensino? Embora a peculiaridade dessa problemática, não se abre mão do problema maior (sem a pretensão de encerrá-lo aqui) que move a constituição do método de investigação: como tratar na pesquisa da atividade de ensino a unidade constituída pelos nexos objetivos e subjetivos, considerada, por nós, determinante da atuação docente?

As manifestações, base da análise desse estudo, decorreram da seleção de recortes de entrevistas com quatro professoras de Matemática Aposentadas (A1, A2, A3 e A4) - ocorridas no período entre 2009 e 2010 - e quatro com Pedagogas que estavam em atividade nos anos iniciais do Ensino Fundamental (B1, B2, B3 e B4) - ocorridas no período entre 2011 e 2012. A entrevista não se caracterizou como um rol de perguntas a serem linearmente respondidas, mas como um instrumento de mediação no diálogo em que entrevistado e entrevistador elaboraram e expressaram pensamentos sobre suas práticas e produções pedagógicas referentes ao exercício da profissão docente. Nesse processo analítico, emerge outra centralidade: os sentidos que elas atribuem à sua atividade e às implicações que a posição da docência reflete em suas manifestações emotivas. Por decorrência, torna possível a identificação do processo bilateral, apontado por Davídov (1988), que ocorre na apropriação do objeto da atividade externa e no processo de transformação para a atividade interna.

O fato de que o contato com as professoras, por meio da entrevista, ocorreu entre 2009 e 2012, não quer dizer que o processo de análise de seus pensamentos tenha, nessa época, finalizado. No decorrer, novas unidades de análise emergiram 
e suscitaram a continuidade da pesquisa (2009-2016) sobre o conhecimento humano passado de geração em geração e a práxis docente no processo educativo. Consequentemente, se apresenta outra unidade de análise correlacionada às práticas e revelações das professoras: o sentido da ação e seu efeito na individualidade docente. Trata-se, pois, das determinações particulares emergentes na atuação docente, ligadas ao motivo e à finalidade da atividade de ensino apreendida pelas professoras.

O pressuposto que orienta essa unidade de análise é de que as condições objetivas da atuação das professoras, principalmente ao ocuparem o lugar da docência, promove sua interação como indivíduo singular com a universalidade da educação escolar. O entendimento é de que nessa unidade a práxis se apresenta tanto objetiva, estabelecida por determinantes da prática social, quanto subjetiva, determinada pelos sentidos que se expressam para o sujeito na particularidade de sua atuação (LUKÁCS, 2012). Desse modo, centraremos a atenção no processo de análise das compreensões manifestadas pelas professoras para essas confluências peculiares à referida unidade de análise. Em vista disso, o foco a seguir está nos principais pressupostos e conceitos da base teórica da pesquisa e de seu método que, de certa forma, adentra ao problema maior da pesquisa.

\section{A objetividade das leis que estruturam a atividade de ensino e o conteúdo da individualidade docente}

Os princípios básicos da perspectiva que fundamenta essa pesquisa geraram, necessariamente, a reflexão sobre o método de investigação adotado, pois se trata da análise de uma prática revelada pela tomada de consciência dos próprios sujeitos da atividade. Nesse contexto, se apresenta o seguinte questionamento: será o discurso sobre uma prática apenas um discurso? As fragilidades, advindas da análise de um conteúdo aparentemente subjetivo, colocam, para nós pesquisadores que pesquisam nesse terreno considerado instável, o desafio de trazer à dimensão concreta da ciência elementos mais 
sólidos como resultado das análises. O risco de relativizar as práticas alicerçadas apenas em manifestações por si mesmas, ou de generalizar as manifestações com base em categorizações frágeis, se torna uma constante linha tênue que necessita ser percorrida. Porém, a escolha não é pelo tangenciamento dessa linha.

Por isso, vale o destaque para a importância da correlação de opostos que origina a unidade indivíduo $\rightleftarrows$ coletividade. Como diretriz da análise, admitimos que a - unidade composta por estas duas categorias - revelam os nexos gerais da prática humana universal (coletividade). Além disso, consideramos o sujeito como ser substancial que revela estes nexos e, ao mesmo tempo, os constitui nas relações particulares que movem com suas práticas (indivíduo). A necessidade de compreender os elementos que agem como impulsores dos sujeitos dessa relação universal-singular entre indivíduo e coletividade, nos remete a centralizar nesse estudo a correlação dos componentes estruturais da atividade humana (LEONTIEV, 2004): necessidade $\rightleftarrows$ motivo $\rightleftarrows$ finalidade.

Um motivo que não coincide com a finalidade própria de uma determinada atividade, ou seja, que não expressa simultaneamente em si mesmo motivo e finalidade, só se torna eficiente quando de algum modo age realmente como impulsor das ações dos sujeitos (LEONTIEV, 2004, p. 318). Somente assim, o indivíduo determina e executa as ações correspondentes sob o impulso do motivo que expressa algum sentido positivo. O salário (objeto de necessidade) pode não se caracterizar como finalidade própria de nenhuma atividade externa. Mas se apresenta, de certo modo abstrato, como motivo eficiente (LEONTIEV, 2004) da maioria das atividades profissionais, pelo sentido concreto que representa na vida dos homens: todo trabalhador, em busca de satisfazer as necessidades pessoais, age realmente na expectativa de obtê-lo no final de cada mês de trabalho.

Mesmo que esse motivo não mostre nenhuma determinação própria da atividade realizada pelos indivíduos, uma contingência concreta de não recebê-lo, gera impulsos de emoção negativa (RUBINSTEIN, 1978), relativa às necessidades individuais que, geralmente, leva-os a interromper a atividade. Afinal, nas relações capitalistas, o salário só é motivo eficiente (motivo que age realmente) ao se concretizar em forma de dinheiro na mão do trabalhador. Os 
impulsos gerados pela relação com o objeto próprio da atividade são ligados ao motivo e à correspondente finalidade das ações da atividade que atende a uma necessidade social. Assim, a existência de impulsos gerados pelos motivos próprios da atividade depende dos sentidos acendidos para o sujeito em sua atuação, relativo ao lugar que ele ocupa na sociedade. O motivo de uma determinada atividade, apropriado pelo indivíduo que a realiza, gera um complexo de sentimentos e emoções positivas com um sentido forte para a atuação. Consequentemente, possibilita־o o desprendimento de esforços com relativa independência sobre o motivo elementar das relações profissionais (o salário) e o coloca numa relação mais concreta com os objetos próprios da atividade.

A atividade de ensino resulta das ações e operações pedagógicas validadas pela estrutura do sistema de ensino que se encerra no processo de avaliação: a aprendizagem (por parte dos estudantes). Ao mesmo tempo, se apresenta como motivo e finalidade, numa relação de coincidência e transformação mútua do objeto que move e orienta o profissional docente (LEONTIEV, 1978). Ao entrarem em atividade de ensino, os professores apreendem o funcionamento da estrutura que abrange a integridade objetiva (DAVÝDOV, 1982) dos nexos externos constituintes do ensino escolar que, objetivamente, é gerado pela necessidade coletiva de formação do gênero humano. Essa relação de tomar para si as razões do ensino escolar ainda se confundem com o motivo salário, que chamamos aqui de elementar, devido à ligação com as horas de trabalho em sala de aula e o tempo de organização do ensino (relação salário versus horas aula).

De modo particular, a apropriação dos nexos da prática pedagógica pelos sujeitos do ensino constitui internamente a individualidade docente. Nessa relação se sintetiza a concretude da consciência docente. Isso porque a intensidade com que professores e professoras vivenciam a prática pedagógica está ligada ao conhecimento dos nexos que satisfazem tal necessidade social. Ao serem apropriados, esses nexos agem na dimensão dos seus desejos e sentimentos determinados pelos "interesses próprios" da atividade de ensino como necessidade individual. Ou seja, a aprendizagem e o consequente desenvolvimento discente 
passam a ser um desejo que move e orienta o professor à atividade, com efeito psicológico de dínamo semelhante ou até maior que aquele gerado pelo salário ao atuar como motivo eficiente (LEONTIEV, 2004).

$\mathrm{Na}$ especificidade das professoras partícipes do presente estudo, seus anseios (necessidades, motivos, finalidades, desejos e sentimentos) e suas produções (ações e operações de ensino) revelam entendimento de que o fazem para que o aluno aprenda, mesmo que os nexos desse processo não se mostrem concretamente para elas. Esse movimento dialético da prática docente revela a dinâmica da estrutura da atividade de ensino como segue na fala de A2:

E porque que eu lecionei matemática? Porque na época faltava professor de matemática. Eu só fiz aqueles cursinhos (de Matemática) que tinham de preparação do estado e até fora do estado. Eles chamavam os professores, que na época lecionavam matemática, e eu entrava junto também com os que já tinham graduação. E como eu estava trabalhando na área eu era sempre indicada e aproveitava a chance (necessidade de sobrevivência relação inicial com o motivo salário). [...] Geralmente começava com probleminhas envolvendo as quatro operações. Os números pares os números impares. Os números primos. Depois os múltiplos. Depois disso tudo dos números, daí ia incluindo os conjuntos (contato com a Matemática: condição da relação profissional conforme o lugar que ocupava e da interação com o objeto da atividade de ensino). [...] Por exemplo, quando eu ia falar sobre metros, eu pedia pra eles trazerem de casa, quem tinha fita métrica, eu tirava as carteiras tudo do lugar na sala e a gente media e eles aprendiam metros, decímetro, centímetro, tudo. Daí eu botava no quadro e eles já sabiam. Eles estavam entendendo, eles estavam gostando (da interação com o objeto da atividade de ensino para as finalidades próprias dessa atividade). [...] Nós temos que fazer um trabalho diversificado, porque quando atinjo a criança individualmente como ela é de onde ela está ela vai embora (aprende e desenvolve). E quanto mais esperto, melhor pra trabalhar. Quanto mais ativo melhor pra trabalhar. Ele vai produzir mais (das finalidades próprias da atividade para as razões que movem a atividade: motivo próprio da atividade de ensino). 
Isso quer dizer que, além de se colocarem em atuação pelo motivo salário, numa relação objetiva da atividade de sobrevivência, na atualidade, há a hipótese de que todo docente entra também em atividade pela relação gerada na interrelação dos componentes peculiares motivo $\rightleftarrows$ finalidade: aprendizagem. Isso causa sentimentos e emoções em suas atuações, não só quando não recebem o salário que desejam. Acima de tudo, quando: o aluno não aprende, a ação não se concretiza com êxito, a escola não lhe dá as condições básicas para atuar, o aluno não se interessa pelo estudo, entre as múltiplas condições determinantes da relação que coincide motivo e finalidade na prática pedagógica. Na relação com a formação dos conceitos a Professora B3 relata:

Quando a criança aprende, tipo hoje, eu tava ali fazendo um chapéu de fada, e agente trabalhou as formas geométricas. Eu procurei trabalhar com aquilo que tenho no planejamento pra seguir. Aí eu fui fazer o chapéu de fada e fui medir na menina e teve duas que falaram: é um cone professora. Então quer dizer, eu sei que ela criou o conceito do que é uma forma geométrica. [...] As figuras geométricas eu trabalho assim, é a primeira coisa que eu trabalho por causa da coordenação motora, formam desenhos com as figuras geométricas. Aí eles sabem que se recortaram começou a ter uma espessura. Então, eu trabalho com eles a questão do que é figura plana, do que é figura espacial, o conceito. Eles já sabem tudo! Faço algumas atividades: vamos pintar triângulo de amarelo porque aí eu trabalho a questão da coordenação, da visualização. Então eu vou trabalhando os conceitos. [...] Quando eu trabalho com segunda série uso muito na multiplicação e na divisão. Mas ali com eles eu trabalho mais no criar conceitos e na adição e subtração. [...] A avaliação diagnóstica eu faço todo dia. Outro dia uma mãe me questionou por que eu tava voltando o conteúdo. Eu disse: eu não estou voltando, a tua filha construiu o conceito, mas dez alunos não construíram o conceito. Eu tenho que pensar nos dez alunos. Pra ela vai reforçar e para aquele lá eu pretendo que ele alcance o conceito. Sou muito criticada por isso.

Aparecem ao menos duas relações objetivas concretas em meio à atuação da Professora B3: 1) a relação de aprendizagem e desenvolvimento do estudante em vista de seu planejamento (uma reflexão interna de autoavaliação sobre a própria atividade com base na significação que tem do motivo e finalidade); 2) a relação com os sujeitos externos a sua aula, mas que atuam também como 
'avaliadores' do processo de ensino aprendizagem, por exemplo, a mãe de uma estudante da classe. A Professora B3 visa ser coerente com o planejamento (não se trata aqui discutir a qualificação do planejamento). Desse modo, a ênfase para B3 está em realizar ações que, de certa forma, logrem alguns êxitos vislumbrados. Essas duas relações correlacionadas são determinantes das reações emocionais da Professora ou por uma postura que revela a concretude das ações práticas realizadas com êxito ou pelo tangenciamento delas quando não se realizaram.

A apropriação do significado da aprendizagem, em que se produz o sentido da atividade de ensino, para professores em geral (LEONTIEV, 2004), constitui a base das emoções e dos sentidos ligados à função da docência em dependência das relações práticas mediadoras desse processo em cada singularidade.

A intensidade das emoções e dos sentimentos depende, em primeiro lugar, do significado que tem para os homens os objetos e fenômenos que os motivam que, por sua vez, depende de como se organiza a vida do sujeito, da importância nela de uns ou outros fenômenos ou atividades, das necessidades principais para ele, de suas atitudes com respeito às exigências sociais, quais motivos o impulsiona e quais as finalidades ele persegue em sua atividade. (BLAGONADEZHINA, 1978, p. 357).

Assim, a aprendizagem na atividade de ensino, devido ao seu duplo efeito de motivo e finalidade (Leontiev, 1978) ligado à necessidade de formação do gênero humano, expressa o verdadeiro sentido das ações pedagógicas, porém, o seu significado se apresenta de distintas maneiras ao indivíduo. Consequentemente, o sentido pessoal e a compreensão do motivo e da finalidade da atividade, determinantes de suas reações emocionais a respeito dela, dependem do contexto particular de sua formação humana e atuação prática. Esse fato objetivo, em torno do sentido pessoal na práxis docente, abre margem para refletirmos: quais parâmetros são necessários para considerar que um professor ou uma professora está em atividade de ensino? A atuação prática em sala de aula se faz suficiente para isso? Esses questionamentos requerem o estabelecimento de parâmetros para uma análise que consideramos mais consistente da atuação prática dos sujeitos da docência. Em outros termos, fazem 
necessária uma correta generalização dessa unidade complexa que se sintetiza na prática pedagógica.

Socialmente, as atividades surgem com motivos ocultos (LEONTIEV, 1978; 2004). Porém, como prática individual, uma atuação sem motivo próprio se torna, no máximo, ação ou operação da dinâmica dos componentes correlativos: atividade $\rightleftarrows$ ação $\rightleftarrows$ operação. Desse modo, não importa para o que se orienta a ação e a operação do sujeito, uma vez que, o sentido está apenas no que vai receber pela realização dos procedimentos. Assim, a atividade que se expressa socialmente se torna diferente da atividade individual apesar de estarem na mesma unidade. A atuação, desse modo, não se concretiza como práxis individual que caracteriza o modelo de atividade social em que está inserido o sujeito.

É no concreto. Tudo o que eu posso fazer no dia a dia do concreto. Se eu puder estar ali trabalhando com eles, o concreto, o material dourado, o ábaco, e o conceito é o que eu me sinto segura. Eu detesto ter que passar uma continha. Eu já trabalhei numa quarta série que os pais exigiram que eu trabalhasse continha. E pra mim foi o "ó" ter que botar uma continha sem ter uma situação problema. Mas infelizmente algumas pessoas ainda tem que a matemática é só aquilo ali. É decorar tabuada, é saber somar, dividir e multiplicar na base da continha e não na base do concreto. (Professora B3).

A fala acima é reveladora do conjunto de múltiplas determinações atuantes na prática docente. Ao assumir determinada postura pedagógica referente à disciplina de Matemática, a Professora assume também um conjunto de significações que dão sentido a sua prática e a orientação da mesma. Isso gera uma relativa autonomia que permite a Professora analisar e questionar certos procedimentos que, em seu rol de significações, não atendem a finalidade da atividade de ensino com base apenas em memorizações de procedimentos. Vale dizer novamente que essa análise não se dirige para a correta postura pedagógica frente aos conteúdos matemáticos, mas para o envolvimento das professoras com sua atividade prática e os possíveis efeitos em sua individualidade. Assim, quando B3 se vê numa situação em que deve operacionalizar o ensino sem que atribua sentido para suas ações, estas se tornam elementos desestimulantes para 
sua atuação. Pode-se dizer que o único motivo eficaz que atua nesse momento é o salário.

Observa-se que, no caso da docência, a relação de coincidência do motivo e da finalidade da atividade, forçosamente, atribui para o indivíduo o nexo concreto de sua função. Ainda que de forma imediata, as conexões das relações objetivas que se expressam para ele revelando possibilidades de sua atuação, os problemas que o movem (necessidade $\rightleftarrows$ motivo) e dos fins que o orientam (objetivos $\rightleftarrows$ tarefas) - são geradoras de sentido dessa prática. A apreensão das referidas objetivações (com níveis diferentes de concretização) se torna conteúdo subjetivo da individualidade docente. Ao apropriar-se delas, tomá-las para si como linguagem, percepção e experiência adquirida, produz um sentido com relação ao que significam. Esse sentido é determinado e subsidia o estabelecimento dos rumos concretos das relações que se estabelecem na unidade constituída pelos componentes peculiares necessidade $\rightleftarrows$ motivo $\rightleftarrows$ finalidade da atividade (DAVÍDOV, 1988; LEONTIEV, 2004). Tal sentido torna-se categórico na pulsão individual, bem como, nos rumos que tomam as ações e operações de ensino.

$\mathrm{Na}$ situação do contexto escolar que segue, a Professora A2 relata uma ocorrência de sua prática pedagógica que revela uma das formas como se manifesta o conteúdo subjetivo da atividade nas relações objetivas de sua realização:

Eu fiz um trabalho de recuperação por vários anos que foi muito gratificante. [...] Foi gratificante porque a gente tinha três aulas seguidas, duas aulas seguidas e dava de fazer um bom trabalho. [...] Chegava à sala de recuperação, tinha que recuperar a matéria de quinta, sexta, sétima e oitava. Vamos supor que eu ia dar fração. Os abençoados (alunos) não sabiam por que era um meio, o que era um meio, o que era um terço, o porquê daquilo. Eu tinha que começar tudo como se fosse na quarta série, na terceira série. Tinha que partir de onde o aluno estava. Daí ia seguindo e ele aprendia, o aluno aprendia. (Professor A2)

Essa manifestação traduz, de certa maneira, o movimento que une os nexos objetivos da atividade (as relações estruturais) com os nexos subjetivos (que expressam traços do conteúdo apreendido pela Professora). Tal afirmação se 
justifica quando A2 relata a posição dos alunos, o tempo de aula e as séries que deveriam ser recuperados os conteúdos. Isso mostra a condição de sua atuação dentro do modelo institucionalizado, o que a caracteriza socialmente como atividade de ensino expressa numa particularidade do contexto escolar. Essa condição, sob as circunstâncias das necessidades, motivos e finalidades da atividade de ensino, bem como seu efeito na individualidade do professor em atividade, determina a nova relação que move e orienta esse docente em sua atuação. As fragilidades conceituais matemáticas dos estudantes e o lugar que lhes é determinado pelo sistema de ensino - classe de recuperação - a revela, para A2, um novo sentido para a sua atuação. A relação com esse sentido, por sua vez, se torna determinante das produções e remodelações das ações e operações de ensino que considera pertinente para aqueles estudantes.

O sucesso da atividade prática como um todo depende da ligação entre as ações e as finalidades significadas objetivamente em sua consciência. A relação concreta, que se estabelece em torno do êxito, atribui o tipo de sentimento e emoção da professora que entra em atividade. Singularmente, A2 expressa um sentimento de gratificação pelo êxito da particular realização da atividade. Porém, apesar da variação do conteúdo com relação às séries dos alunos em recuperação, ele segue um modelo pedagógico. Assim, o êxito determinante do seu estado emocional (Rubinstein, 1978), igual ao sentimento de gratificação pelo resultado positivo de seu 'trabalho', refere-se ao cumprimento desse modelo de ensino. A aula de recuperação, que nesse caso se tornou uma condição dentro da estrutura escolar, conservou a aprendizagem com o caráter de motivo e finalidade. Por isso, a professora reestrutura suas ações e operações para atender o que considera ser necessário o aluno aprender, de acordo com os seus objetivos pessoais em consonância com aqueles estabelecidos pela escola que, por sua vez, traduzem as determinações dos órgãos oficiais.

Embora não empreendemos a discussão quanto à validade dos parâmetros científicos da educação escolar, referente à proposição do ensino de terceira e quarta série, manifestada por A2 em "partir de onde o aluno estava", consideramos de suma importância os elementos que caracterizaram essas ações 
como práxis pedagógica e, consequentemente, como realização da atividade de ensino. Trata-se de identificar na atuação mencionada o motivo da atividade (aprendizagem), bem como os indícios de que as ações realizadas se orientam para essa mesma finalidade (aprendizagem). Assim, independente do conteúdo das ações, pode-se pensar na ocorrência de uma práxis que se caracterize como atividade de ensino.

Vale esclarecer que toda proposição de ensino, que adota como matriz teórica o materialismo histórico e dialético, defende como papel da escola promover a aprendizagem de conceitos com teor científico (Davídov, 1988). Assim, a finalidade do modelo de práxis social de ensino tem um conteúdo pertinente ao que Marx e Lênin defenderam como modelo de práxis revolucionária: igualdade e emancipação dos homens. No entanto, o ponto de partida de ambos não pode perder de vista a atividade prática atual do homem e, respectivamente, o modelo de práxis social vigente. Apenas assim, pode-se pensar: no projeto transformador para a educação; qual a educação deve ser superada; o que deve mudar na atividade de ensino atual, etc..

Nessa perspectiva, considera-se a práxis como o movimento dinâmico da relação do sujeito com a realidade concreta e não como uma forma mecânica de realização perfeita de um modelo teórico. Portanto, ainda que o professor compreenda concretamente o processo de aprendizagem e tenha se apropriado da significação mais evoluída da finalidade de sua atividade, sua práxis é determinada, primeiro, pela condição objetiva de sua atuação. $O$ fato de o professor entrar em atividade de ensino não garante o desenvolvimento da aprendizagem científica do aluno, que depende: das condições de estudo do estudante, da estrutura escolar, de como o professor se apropria das significações da educação escolar e, principalmente, do conteúdo das ações que ele realiza ao propor as tarefas e promover as ações do estudante (DAVÝDOV, 1982).

A significação e o sentido da aprendizagem, para os professores em geral, aparecem como determinantes das ações e operações de ensino, tanto no que se refere ao seu efeito de motivo quanto no de finalidade. Isso se traduz no empenho 
à atividade e na preocupação com os seus resultados, como se observa na fala de B1:

A gente tinha muita reunião do colégio, muita reunião pedagógica, não é como hoje. A reunião pedagógica era fora do horário da aula. A gente participava das reuniões, estudava, preparava todas as aulas juntas. A gente via os resultados e tinha consciência que fazia um bom trabalho. [...] Não basta só querer, você tem que ter a formação, o embasamento teórico, tem que compreender como a coisa acontece, não é só de boa vontade que se faz educação. Acho que é muito importante ter essa fundamentação teórica e vá fazendo essa interação com a prática, significando uma a outra, fazendo essa interlocução entre prática e teoria. (Professor B1).

Essa fala é esclarecedora de que o professor em atividade, além da relação do motivo $\rightleftarrows$ finalidade, também expressa as condições para tal (embasamento teórico), as ações e operações de ensino no âmbito coletivo (reuniões pedagógicas), bem como as limitações que se apresentam a sua vontade (não basta querer). A ligação que tem com os objetivos que propôs determina seu nível emocional. Todo esse movimento se dá no plano prospectivo para atingir a aprendizagem dos estudantes. Nesse caso, quando o aluno aprende aquilo que ele planejou e executou em sua aula, sua atividade "enche" de sentido e gera emoções positivas e sentimentos "bons" que reforçam o seu motivo (RUBINSTEIN, 1978; BLAGONADEZHINA, 1978). Caso contrário, ocorre uma ausência de sentido na atuação, que determina tipos de emoções negativas e sentimentos "ruins" que enfraquecem o motivo.

Essa relação com o sentido leva a reflexão para duas vias. Por um lado, é possível que o professor desloque o sentido de sua atividade somente para o salário que recebe. Ou seja, não entra em atividade de ensino - mesmo que esse ato se apresente, psicologicamente, como um mecanismo de defesa (consciente ou inconscientemente). Com isso, a aprendizagem do aluno não faz diferença alguma para ele. Por outro lado, na ausência de sentido, o professor pode atribuir outro significado à finalidade do ensino com nova concepção, mais adequada à realidade em que se encontra. Nesse caso, ele permanece em atividade de ensino, tendo a aprendizagem como expressão de motivo e finalidade. Porém, com o conteúdo, 
considerado necessário, que embora se manifeste na atuação individual, decorre das diversas abordagens e práticas educacionais mais vigentes para o professor.

O professor, que entra realmente em atividade de ensino, busca o sentido de sua função. No entanto, a relação do seu motivo com a finalidade se transforma conforme sua condição no momento histórico do ensino. Junto com a sociedade, as concepções e a prática de ensino se transformam, concomitantemente, com as condições de desenvolvimento da consciência do professor. Assim sendo, o sentido também se modifica de acordo com a época, com o meio social e com o contexto de formação do professor. Isso fica evidente nas falas, a seguir:

Eu vejo que a Matemática é importante porque é uma questão de lógica de pensamento, de memorizar e, na vida, a gente precisa bastante. [...] A gente dizia que três vezes três são nove, mas nunca pegamos as bolinhas e fizemos os três vezes três são nove. Não era feito isso aí. Era aquilo ali e pronto. Eu aprendi assim sem ver e depois fui mudar alguma coisa dentro quando fui professora. [...] Naquele tempo era coisa de quadro, giz e o livro. A questão do filme, que é bastante usado, até um canto, bastante coisa. Essa abertura aí foi boa dentro da educação. (Professor A1).

A matemática é uma disciplina que tem que fixar, porque se não dá fixação, eles não aprendem. Eles aprendem, mas eles esquecem logo. Eu era chata com isso, dava muito exercício. (Professor A3).

A Matemática está presente em nosso dia a dia. E principalmente pra quem está estudando, porque muitas matérias são relacionadas com ela. Tudo que envolve cálculo envolve Matemática. É uma coisa que eu acho importante, que os professores se conscientizem que não é só passar matéria. E sim que façam que os alunos realmente aprendam. Sentir que o aluno aprendeu. Pra dar Matemática tem que trabalhar com o coração, embora seja uma ciência exata. Tens que querer que o aluno aprenda. (Professor A4).

A Professora A1 menciona que sua formação teve como fundamento uma concepção que Fiorentini (1995) denomina de formalista clássica, explicitada, por exemplo, em “A gente dizia que três vezes três são nove' somente como um processo de memorização mecânica. Porém, aponta sua compreensão atual de 
teor pragmatista, empírico ativista (Fiorentini, 1995), ao completar sua manifestação: "mas nunca pegamos as bolinhas e fizemos os três vezes três são nove”. A mesma perspectiva e vontade de adoção do modo de organização do ensino de matemática - que prima pelos preceitos empíricos utilitaristas da matemática - é indicado por A4, principalmente, nas seguintes afirmações: "A Matemática está presente em nosso dia a dia" e "Tudo que envolve cálculo, envolve a Matemática”. Por sua vez, a vontade de A3 se afirma na convicção de que a fixação por repetição - peculiaridade formalista clássica (FIORENTINI, 1995) - é o requisito essencial para a aprendizagem. A manifestação representativa de que seu desejo foi manter-se no mesmo lugar pedagógico é: "Eu era chata com isso, dava muito exercício".

Essas falas, das professoras aposentados de Matemática, revelam algumas expressões do sentido que elas conferem às ações de ensino do conteúdo matemático, ligado ao tipo de aprendizagem dos estudantes. Nelas se revelam os conhecimentos e crenças desse processo determinante da sua atuação. A transformação e a diversidade das significações da aprendizagem, por sua vez, determinam os sentidos das ações e operações de ensino para o professor. Revelase aí como o conteúdo da estrutura externa da atividade age na estrutura da atividade interna do sujeito (LEONTIEV, 2004).

A atividade não se modifica independente da vida coletiva dos homens, mas inerente a ela. A sociedade de hoje não tem as mesmas características daquela de vinte, trinta anos atrás, ainda que possam se estruturar sob a mesma base. A situação é idêntica se tomarmos como referência as possibilidades que, historicamente, surgem para a organização do ensino, pois tendências se apresentam em atendimento às necessidades sociais (Fiorentini, 1995). São elas que se apresentam aos professores, por exemplo, A1 e A4, como indicadoras de uma possível satisfação de necessidade de superação de tarefas e ações que, no entendimento delas, não satisfizeram mais o motivo eficaz da atividade de ensino: a aprendizagem dos estudantes. 
Consequentemente, mudanças pontuais no trabalho, na família nas relações de pais e filhos, na escola, nas tecnologias, etc., criam novas condições pedagógicas. Esse tipo de transformação aparece nos relatos de B4.

$\mathrm{Na}$ escola multisseriada, eu tive uma experiência muito boa. Eu tenho muitas saudades daquela escola, os alunos tinham muita vontade e tudo o que eu ensinava parecia que eles aprendiam. Hoje, eu acho que os alunos estão muito acomodados, tem preguiça de pensar. Eles faziam mais esforço mental para aprender. É por isso que, às vezes, a gente diz que o nível dos alunos está baixando. A gente se angustia com isso. [...] Antigamente, nós tínhamos o ensino fundamental de oito anos. O aluno que não aprendesse em cada série repetia, e as dificuldades dele eram sanadas naquela série. Hoje, o aluno da primeira série que não aprende, passa. O aluno da segunda série que não aprende, passa. $\mathrm{Na}$ terceira série, o aluno não aprendeu, retém. Então o que acontece com a terceira série de hoje? Agente chama de turma da peneira. É onde reteve aquele aluno que não conseguiu se alfabetizar. Aqueles alunos que têm as maiores dificuldades. Então se torna uma turma pesada para o professor trabalhar. (Professor B4)

A mudança na condição da aprendizagem do aluno - ou a divisão em dois grupos de estudantes: aprendem ou não por um determinado modo de organização do ensino - contribui para o sentimento de frustração da professora, gerado por não obter o êxito no ensino com as novas circunstâncias. Essas mudanças implicam no sentido da sua atuação, pois o que faz não causa mais o resultado anterior. O seu sentimento é expressão da compreensão de que as características gerais da educação escolar se voltam para que o aluno entre em atividade de estudo (Davýdov, 1982). Porém, mesmo que não compreenda esse processo, a "simples" mudança do que motiva o aluno à atividade, do seu caráter perante o estudo, se torna determinante da atividade da professora. Assim sendo, a condição social e estrutural da escola é determinante das novas expectativas docentes de estimular, de alguma forma, o aluno a estudar. As estratégias de estabelecimento das ações e operações apontam para esse objetivo como relata B2: 
Quando tu fazes um trabalho assim (se tratando de um jogo com varetas para ensinar multiplicação) é ótimo, mas nem sempre o resultado é positivo, tu ficas assim, será que vai dar certo? Quando eu vi que ele tinha conseguido mesmo - ele não sabia, ia para o quadro e chegava a suar o giz na mão, não fazia. Precisava brincar se descontrair pra aprender, e ele conseguiu isso - ganhei o dia. Ganhei o dia quando ele chegou e me disse a tabuada toda, aí todo mundo bateu palma. Ele se sentiu o máximo na sala, porque uma criança quando aprende a gente tem mais é que incentivar. Mas foi o máximo, para mim, aquilo. (Professor B2)

A aprendizagem continua com seus efeitos estruturais, porém, essa relação fica mais abstrata. O conteúdo concreto do aprender (as tarefas, ações, operações, estratégias, as formas de apropriação, a prática etc..) se mostra de maneira superficial, porém, objetiva e determinante da atuação docente. A fala de B2 traz evidência do pressuposto de Leontiev (2004) de que as apropriações humanas ocorrem a partir de uma prática dada socialmente. Ou seja, a internalização é sempre de algo externo, fruto das relações humanas. Isso porque ele revela uma das visões mais comuns que se percebe na atualidade (no meio acadêmico e na escola) em vista dessas tentativas de estímulo direto: que o aluno desenvolva o gosto pelo estudo e o professor pelo ensino. No entanto, não se trata de excluir esse sentimento da atividade, pois, como foi visto na reflexão sobre a dimensão do desejo, este e os demais sentimentos podem se tornar a base das necessidades e das emoções humanas. A questão que se apresenta é se esse gostar contém o necessário processo para que efetivamente ocorra a aprendizagem escolar. Portanto, não está em jogo o gosto do aluno, mas o que necessariamente ele deve aprender na escola.

\section{Considerações finais}

O olhar analítico sobre as manifestações - explicitadas no texto referentes à prática pedagógica, permite a afirmação de que existe um conteúdo objetivo, gerador de sentido determinantes para a atuação do professor em 
atividade de ensino. As caraterísticas desse conteúdo remetem: 1) aos componentes básicos estruturais da atividade humana, que são gênese e desenvolvimento (LEONTIEV, 2004); 2) o processo de mediatizações inerentes à sua atuação. Tais características revelam o que Davýdov (1982, p. 308, grifos do autor) denomina de "integridade objetiva, existente nas conexões das coisas singulares, o concreto". A unidade dessas duas caraterísticas do conteúdo da atividade, no caso a de ensino, revela que prática pedagógica das professoras, referenciadas no presente texto, apresentam "a plena diversidade de manifestações do todo" (idem). Isso porque as professoras expressam suas necessidades, motivos e finalidades, decorrentes das condições objetivas em que produzem suas ações e operações de ensino, bem como os sentidos gerados pela atuação nesse processo.

A totalidade que integra as múltiplas determinações da prática pedagógica apresenta, para as professoras referenciadas e para qualquer professor em atividade de ensino, um complexo que revela leis gerais que movimentam suas práticas. Ou seja, conferem formas, mais ou menos estruturadas, que agem intimamente ao conteúdo que se apresenta no conjunto de nexos singulares que emergem em cada contexto particular de atuação. Consequentemente, se apresenta outra unidade de análise correlacionada às práticas e revelações das professoras: o sentido da ação e seu efeito na individualidade docente. Trata-se, pois, das determinações particulares emergentes na atuação docente, ligadas ao motivo e a finalidade da atividade de ensino apreendida pelas professoras.

Nessa relação com a aprendizagem, está o que deve se cumprir, com ou sem vontade. A leitura, por exemplo, é sumamente necessária para o desenvolvimento do conhecimento científico. Então, ainda que não desenvolva o interesse por um conteúdo específico e o gosto por essa tarefa, requer a consciência do aluno da efetivação dessa leitura, o que exige dele determinado esforço para que aprenda. Além do mais, exige a compreensão, por parte do estudante, de não se tratar apenas de uma leitura de quando está em atividade de lazer, e sim, daquela que busca os nexos dos conceitos em processo de apropriação. 
O mesmo ocorre com o professor, em atividade de ensino, que não se priva dos conceitos científicos, com a justificativa de que não gosta de "trabalhar" com determinados conteúdos escolares. Para cumprir, verdadeiramente, com sua função, entrar em atividade de ensino e realizar uma práxis pedagógica efetiva, os conteúdos de suas ações e operações - que concretamente estruturam suas aulas - necessariamente, dirigir-se-ão à aprendizagem científica do aluno. Mesmo em condições desfavoráveis do seu contexto escolar, como mostraram as falas dos sujeitos dessa pesquisa, compete ao professor a busca por métodos mais evoluídos de ensino (não os mais fáceis). Além disso, exigi-lhe, na posição de profissionais, compreender as condições objetivas para a realização da atividade. É, sem dúvidas, uma tarefa árdua. Porém, necessária do ponto de vista daqueles que defendem que a escola, como instituição pública de ensino, deve formar e possibilitar a emancipação dos alunos, para que lutem por uma sociedade mais justa e igualitária.

Trata-se da compreensão de que só por meio do conhecimento evoluído que se pode desenvolver o pensamento mais elaborado. A defesa com relação à igualdade de oportunidades, que compactua nesse trabalho, é pela possibilidade de que todos os humanos tenham acesso às condições de desenvolvimento do pensamento teórico. Ao se referir a todos os humanos, inclui o professor que, por sua vez, necessita desenvolver esse pensamento no âmbito daquilo que é mais vital em sua função: ensinar. Mas isso o coloca no compromisso de desenvolver a vontade e o desejo de aprender e pensar crítica e estrategicamente: as possibilidades de suas aulas, a apropriação do conhecimento pelo aluno, as condições do ensino, etc., do mesmo modo que um médico e qualquer outro profissional devem pensar a sua prática. O conteúdo da subjetividade docente que correlaciona intima e singularmente as razões e emoções com relação à atividade de ensino - necessariamente, vincula-se à apropriação dos verdadeiros nexos do processo de ensino e aprendizagem. Somente assim, o professor pode se tornar o 'dono' de sua aula e não entregá-la como uma simples e questionada mercadoria. 


\section{Referências}

BLAGONADEZHINA, L. V. Las Emociones y los Sentimientos. In: Smirnov, Leontiev, Rubinshtein e Tieplov. Psicologia. Traducción de Florencio Villa Landa. 4. ed. México: Grijalbo, 1978, 355-384 pp.

DAVÝDOV, Vasili. Tipos de generalización en la enseñanza. 3. ed. Habana: Pueblo y Educación, 1982. 489p.

DAVÍDOV, Vasili. La Enseñanza Escolar y el Desarrollo Psiquico: investigacion psicológica teórica y experimental. Traducción de Marta Shuare. Moscu: Progreso, 1988.

FIORENTINI, D. Alguns modos de ver e conceber o ensino da Matemática no Brasil. In: Zetetiké, ano 3, n 4, Campinas, UNICAMP, 1995.

LEMOS, Lucas Vieira. A Atividade do Professor e a Matemática no Ensino Fundamental: Uma Análise Sócio Histórica de Sua Estrutura e Conteúdo. 2014. 154 f. Dissertação (Mestrado) - Universidade do Extremo Sul Catarinense, Programa de Pós-Graduação em Educação, Criciúma.

LEONTIEV, Alexis Nikolaevich. O desenvolvimento do psiquismo. Tradução de Rubens Eduardo Frias. 2. ed. São Paulo: Centauro, 2004, 356 p. . Actividad, Conciencia y Personalidad. Buenos Aires: Ciencias del Hombre, 1978.

LUKÁCS, György. Para uma ontologia do ser social I. Tradução de Carlos Nelson Coutinho, Mario Duayer e Nélio Schneider. São Paulo: Boitempo, 2012, 431 p.

RUBINSTEIN, J. L. Principios de psicologia general. Traducción de Sarolta Trowsky. Mexico: Grijalbo, 1978, 767 p. 